\title{
Involvement of male genitalia in leprosy
}

\author{
BHUSHAN KUMAR, INDERJEET KAUR, RANJU RAI, \\ SANJAY K. MANDAL \& VINOD K. SHARMA \\ Department of Dermatology, Venereology and Leprology, \\ Postgraduate Institute of Medical Education and Research, \\ Chandigarh-160 012, India
}

Accepted for publication 24 October 2000

\begin{abstract}
Summary Four hundred and sixty-seven male patients with leprosy were screened for genital involvement. Genital lesions were observed in $6.6 \%$ of all male cases of leprosy. They were seen most frequently in lepromatous leprosy $(25.8 \%)$, followed by borderline lepromatous (13.3\%) and borderline tuberculoid (1.4\%) leprosy.
\end{abstract}

\section{Introduction}

Although involvement of the male genitalia, particularly of the gonads, is well known in leprosy, lesions of leprosy are not commonly found on the genital skin and there have been only a few reports of such involvement. ${ }^{1}$ We screened 467 male patients with various types of leprosy to assess the incidence of lesions on the genitalia.

\section{Materials and methods}

Four hundred and sixty-seven adult males (new, untreated or under treatment) attending our Leprosy Clinic during the period March 1993 to July 1999 were screened for genital lesions. Detailed history, clinical examination, slit-skin smears and skin biopsies were carried out in all patients as part of the routine work-up. Patients were classified according to the revised classification proposed by the Indian Association of Leprologists. ${ }^{2}$ These patients were also examined carefully for the presence of genital lesions.

As biopsies done initially in six cases did not reveal any special feature different from those seen in the cutaneous lesions, no further biopsies were done. The possibility of all other diseases which could result in genital lesions, including sexually transmitted diseases, was considered and excluded by appropriate tests.

Correspondence to: B. Kumar (e-mail: kumarbhushan@hotmail.com) 


\section{Results}

There were $293(62.7 \%)$ patients with borderline tuberculoid (BT) disease, $143(30.6 \%)$ had borderline lepromatous (BL) and $31(6.6 \%)$ had lepromatous (LL) disease. Out of 467 patients, only $31(6.6 \%)$ had lesions on the scrotum or penis either alone or on both the sites. Lesions on external genitalia were present in four out of $293(1.4 \%)$ patients with borderline tuberculoid (BT), 19 out of $143(13.3 \%)$ patients with borderline lepromatous (BL) and eight out of $31(25.8 \%)$ patients with lepromatous (LL) disease (Table 1). Mean age of the affected men was $31 \pm 8.5$ years and the mean duration of disease was $6.0 \pm 2.8$ years. Seven patients were in reaction (BT-2, BL-3, LL-2). Five patients (BT-2, BL-3) had type 1 reaction and two patients with LL disease had type 2 reaction.

In BT patients, the lesions were in the form of ill-defined hypopigmented patches and well defined indurated erythematous plaque on the scrotum (Figure 1). Two out of four BT patients with prominent genital lesions showed evidence of type 1 reaction.

Scrotal involvement in the form of poorly to well defined infiltrated papules and plaques was seen in BL patients (Figure 2). Three of the $19 \mathrm{BL}$ patients had type 1 reaction and in these cases the scrotal lesions were more erythematous and oedematous (Figure 3). One BL patient had prepucial lesions leading to non-retractibility of the prepuce. One patient with BL leprosy with histoid lesions had prepucial involvement (Figure 4). Fourteen (73.7\%) out of 19 patients with BL leprosy had both scrotal and penile lesions.

In LL patients the involvement was in the form of diffuse infiltration and infiltrated papules and plaques (Figure 5). Two out of eight LL patients with genital lesions had ENL lesions on scrotum, out of which one had necrotic lesions on glans penis (Figure 6). Three out of eight $(37.5 \%)$ LL patients had penile and scrotal involvement and four (50\%) patients had penile involvement alone. One LL patient also had a prepucial lesion with difficulty in retraction.

\section{Discussion}

Involvement of genital skin in leprosy has not been studied widely, largely because of the difficulty in examining patients in totality in routine clinical set-ups. Although no part of the skin is immune from invasion by Mycobacterium leprae, ${ }^{3}$ the scrotal skin has been described as an unusual site for leprosy. ${ }^{4} M$. leprae has been found in the dartos muscle even after adequate therapy. ${ }^{5}$ It is difficult to believe, however, that $M$. leprae located in the dartos muscle could in any way contribute to the production of lesions on the scrotum. Pandya and

Table 1. Type of disease and site of genital lesions in patients with leprosy

\begin{tabular}{|c|c|c|c|c|c|}
\hline \multirow[b]{2}{*}{ Type of disease } & \multicolumn{3}{|c|}{ Location of lesions } & \multirow[b]{2}{*}{ Penile } & \multirow[b]{2}{*}{ Total $(\%$} \\
\hline & No. of patients & Scrotal + penile & Scrotal & & \\
\hline BT & 293 & 2 & 2 & - & $4(1.4)$ \\
\hline BL & 143 & 14 & 2 & 3 & $19(13.3)$ \\
\hline LL & 31 & 3 & 1 & 4 & $8(25.8)$ \\
\hline Total & 467 & & & & $31(6.6)$ \\
\hline
\end{tabular}




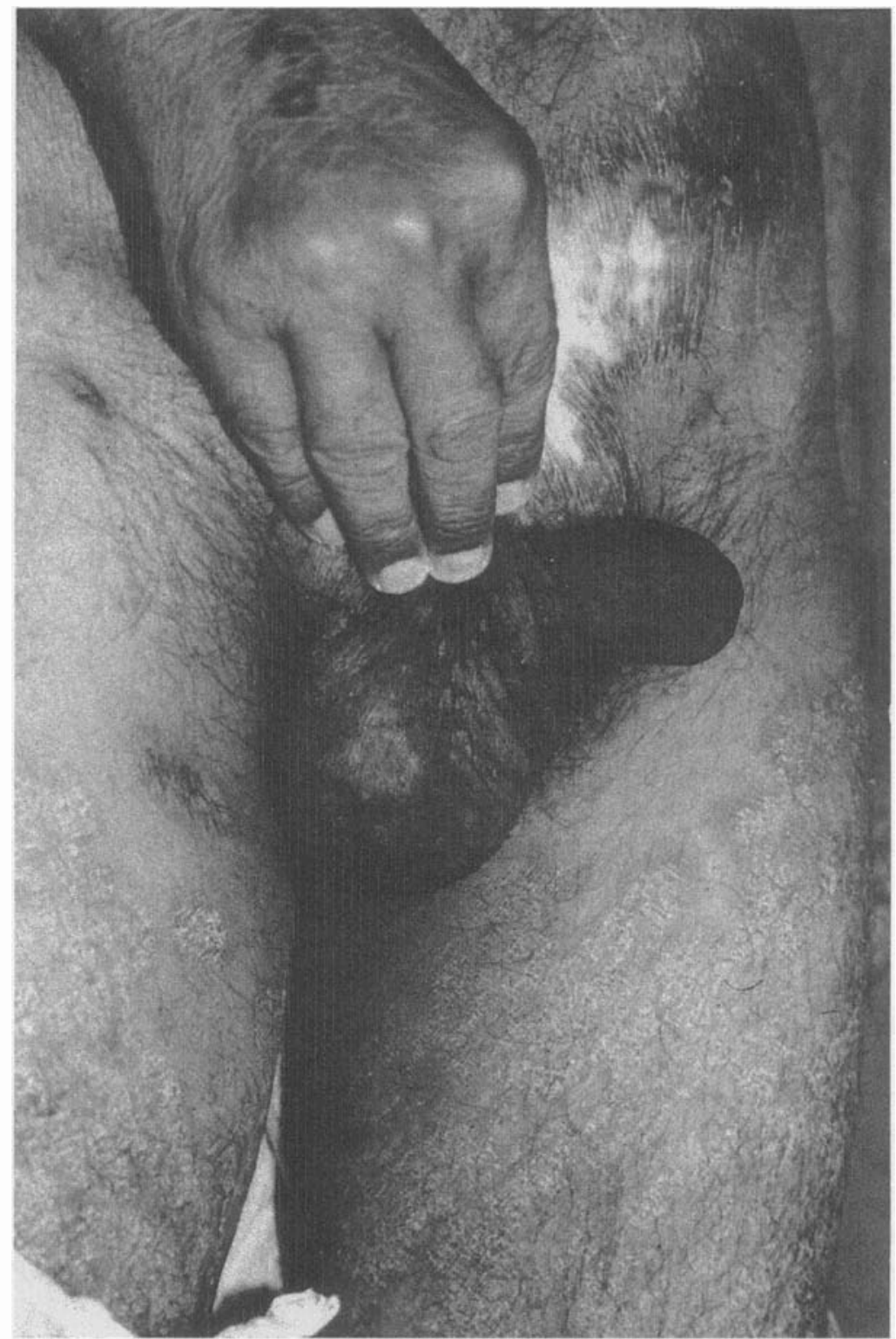

Figure 1. Plaque of BT leprosy in reaction on the scrotum.

Antia ${ }^{6}$ have reported leprous granulomas and AFB in one-third of biopsies from the scrotal skin in patients (treated and untreated) with all types of leprosy even in the absence of lesions on the scrotum. According to Anish, ${ }^{7}$ dermal infiltrate occurs more in cooler areas of the body than in regions close to the higher core body temperature. Scrotal skin has been reported to be relatively cooler than the core temperature under experimental conditions. ${ }^{8}$ However, due to the use of heavy undergarments, it is likely that the temperature of the scrotal skin may 


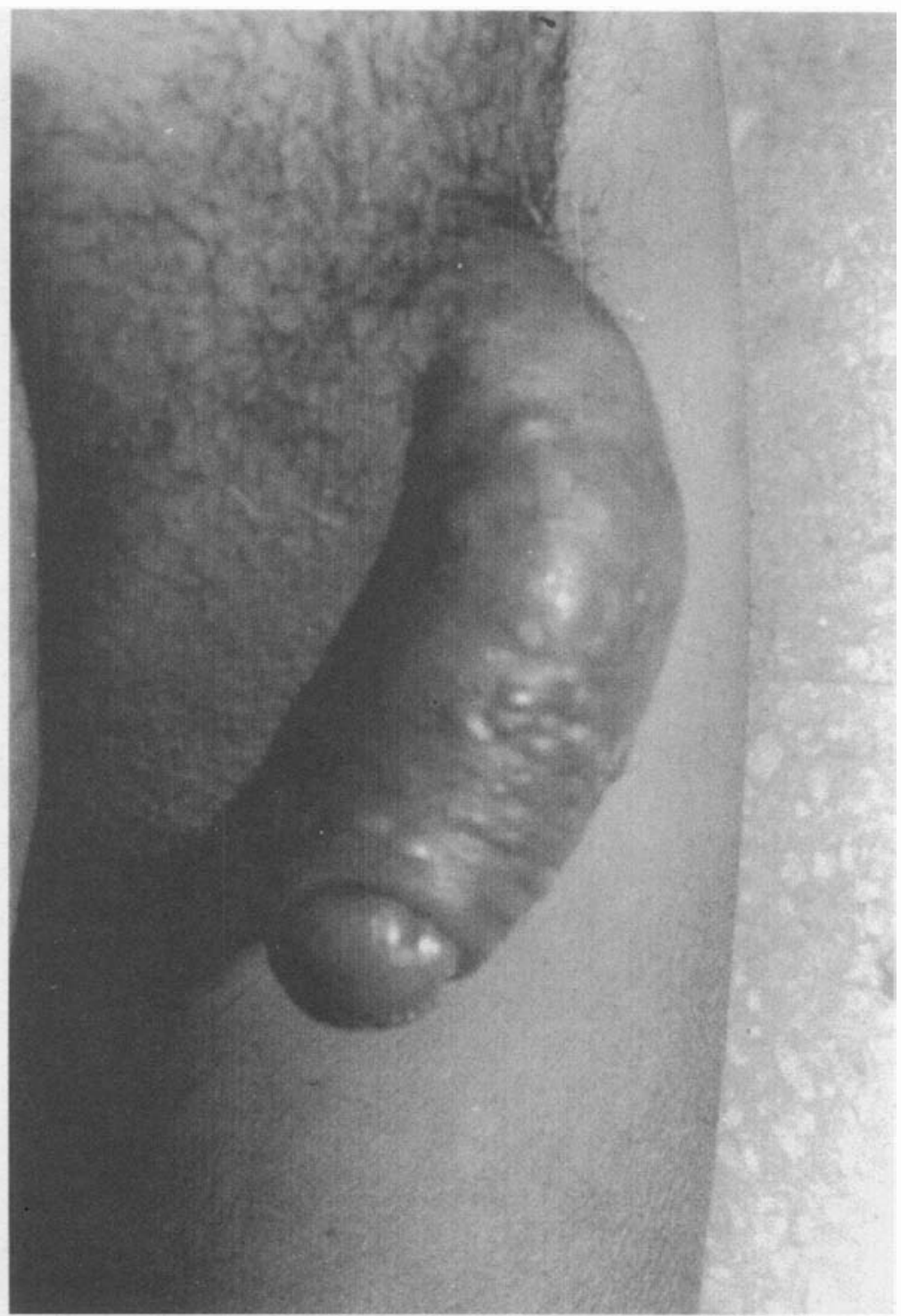

Figure 2. Infiltrated papules over the scrotum in a patient with BL.

remain elevated. Increased temperature may possibly make this area less prone to the development of leprosy lesions.

We have detected lesions in all types of leprosy except TT. Genital involvement in TT patients seems to be rare and we could find only a single case report of this nature in the literature. ${ }^{9}$ Arora et al. ${ }^{4}$ found genital lesions in $2.9 \%$ of the cases with borderline disease but did not detect genital lesions in the tuberculoid group. Most of their patients with genital lesions were in the BB group (61.5\%), whereas most of our patients belonged to the BL 


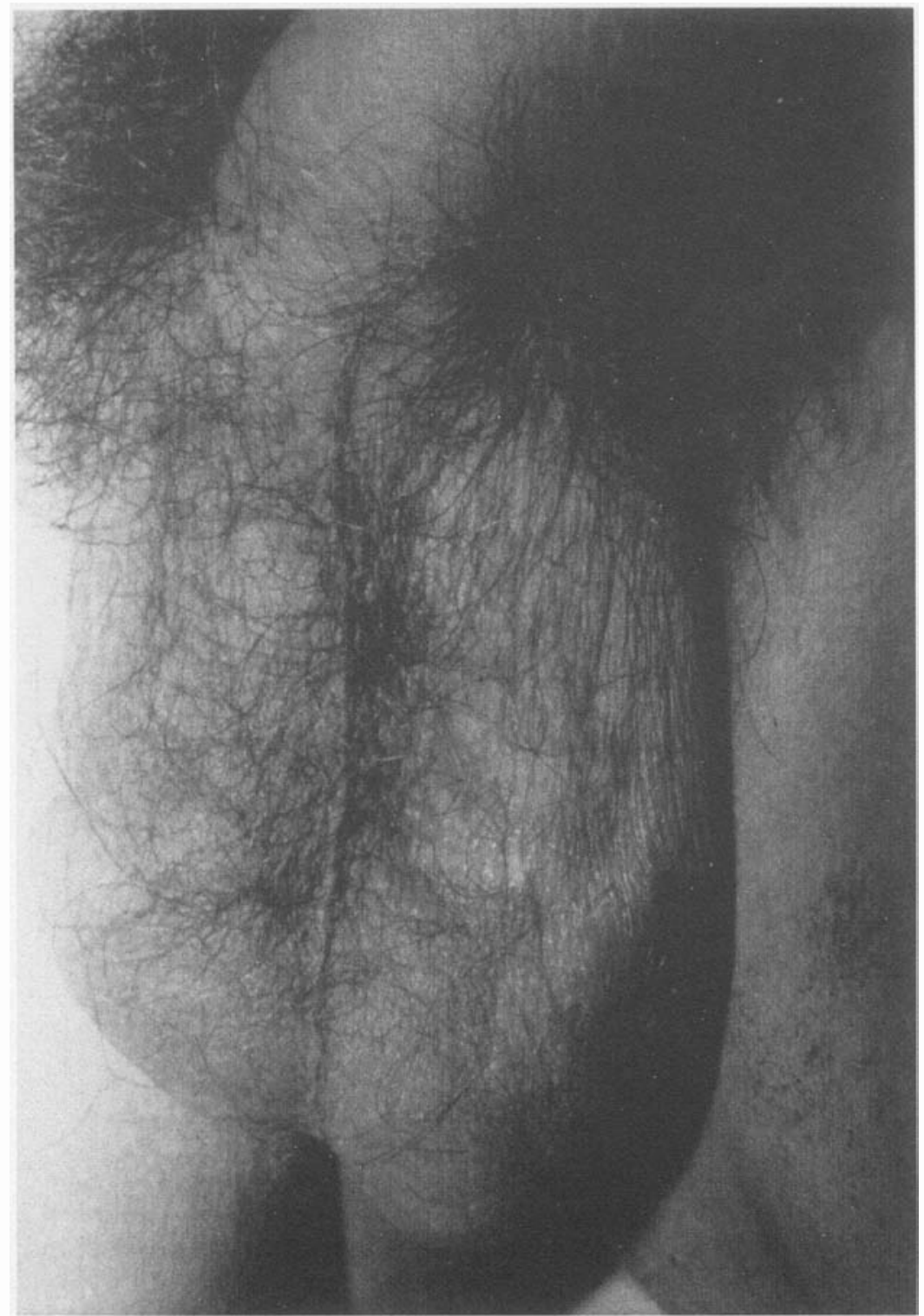

Figure 3. Lesions of BL in reversal reaction on scrotum. Scaly lesions with evidence of subsiding reaction are evident on the thighs.

group. Very rarely, genital lesions in histoid leprosy have also been reported. ${ }^{10,11}$ We too found a patient of BL disease with histoid lesions with prepucial involvement.

The incidence of $6.6 \%$ for genital lesions in our study indicates that such lesions are not as uncommon as reported previously. ${ }^{4}$ They are, however, likely to be missed if not looked for carefully. Their recognition becomes important because genital lesions produced by other diseases may require more serious attention than mere identification. 


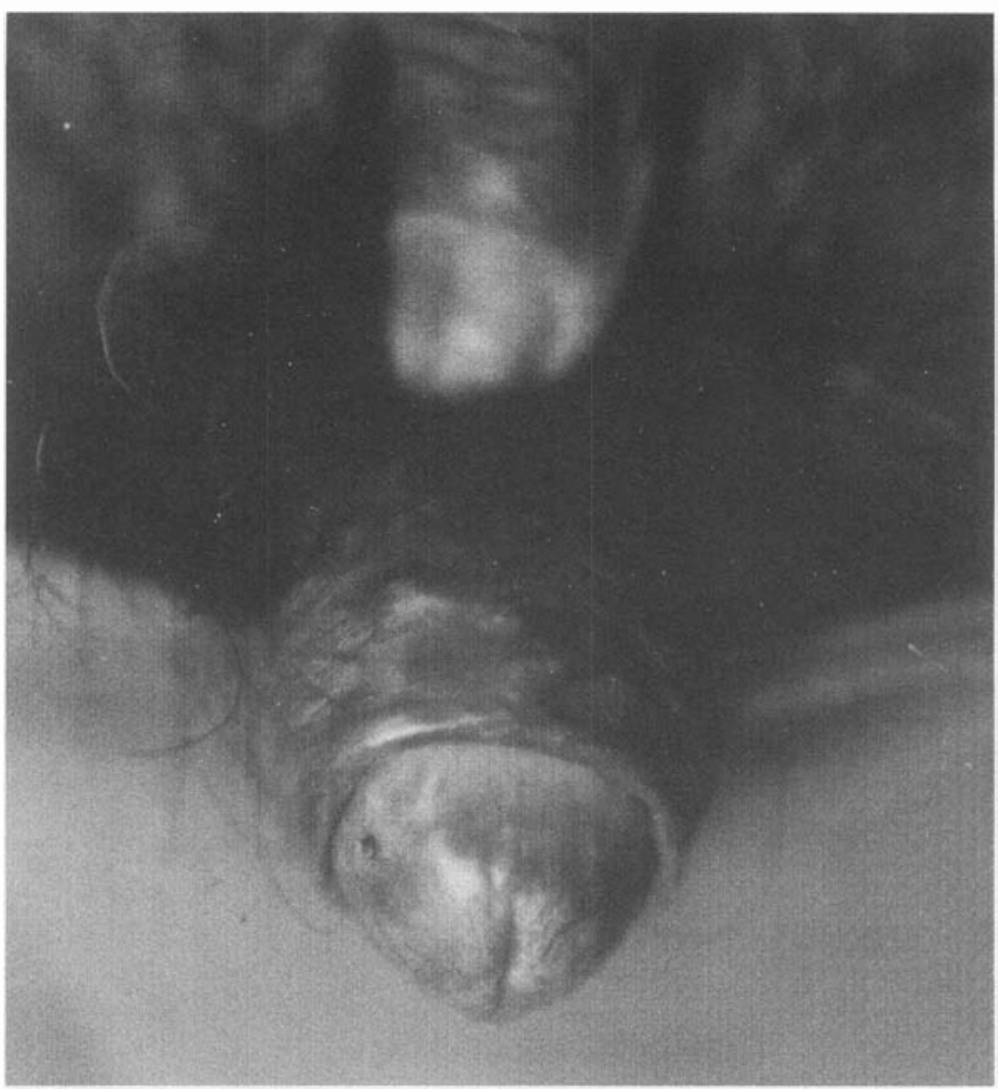

Figure 4. BL leprosy with histoid lesions on the shaft.

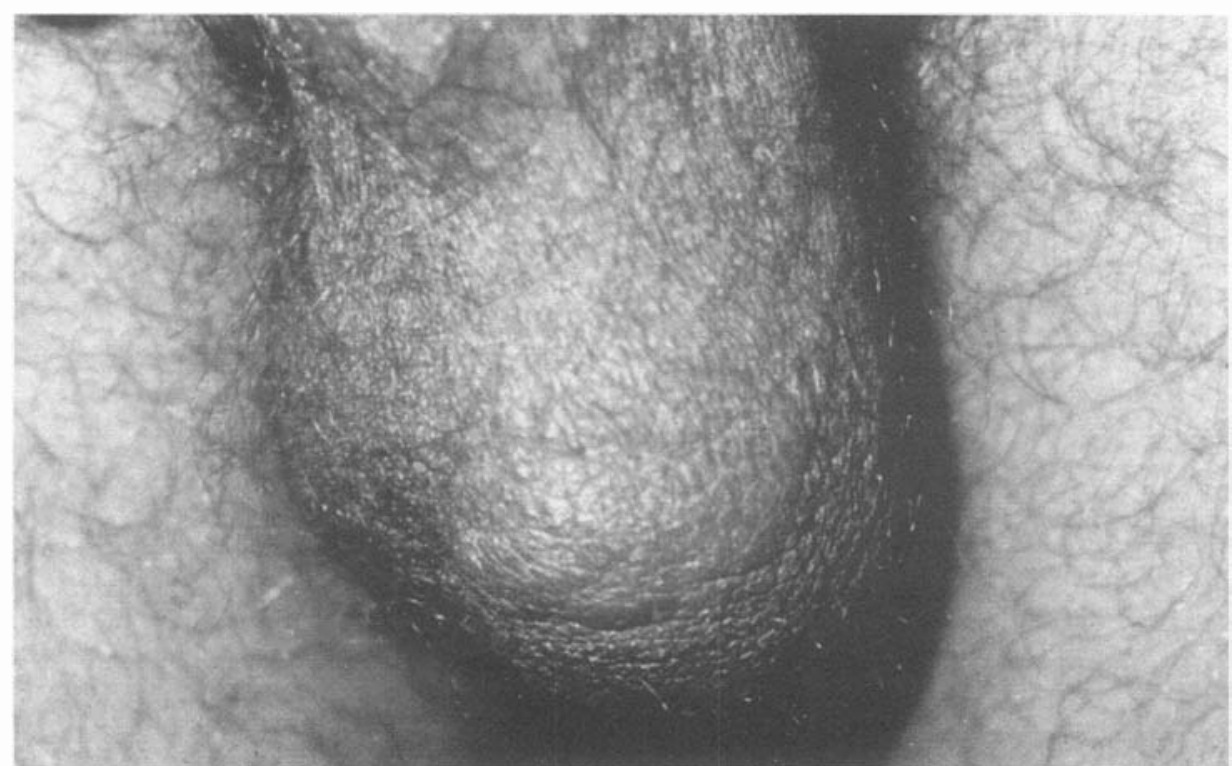

Figure 5. Infiltrated plaque lesion on the scrotum in LL leprosy. 


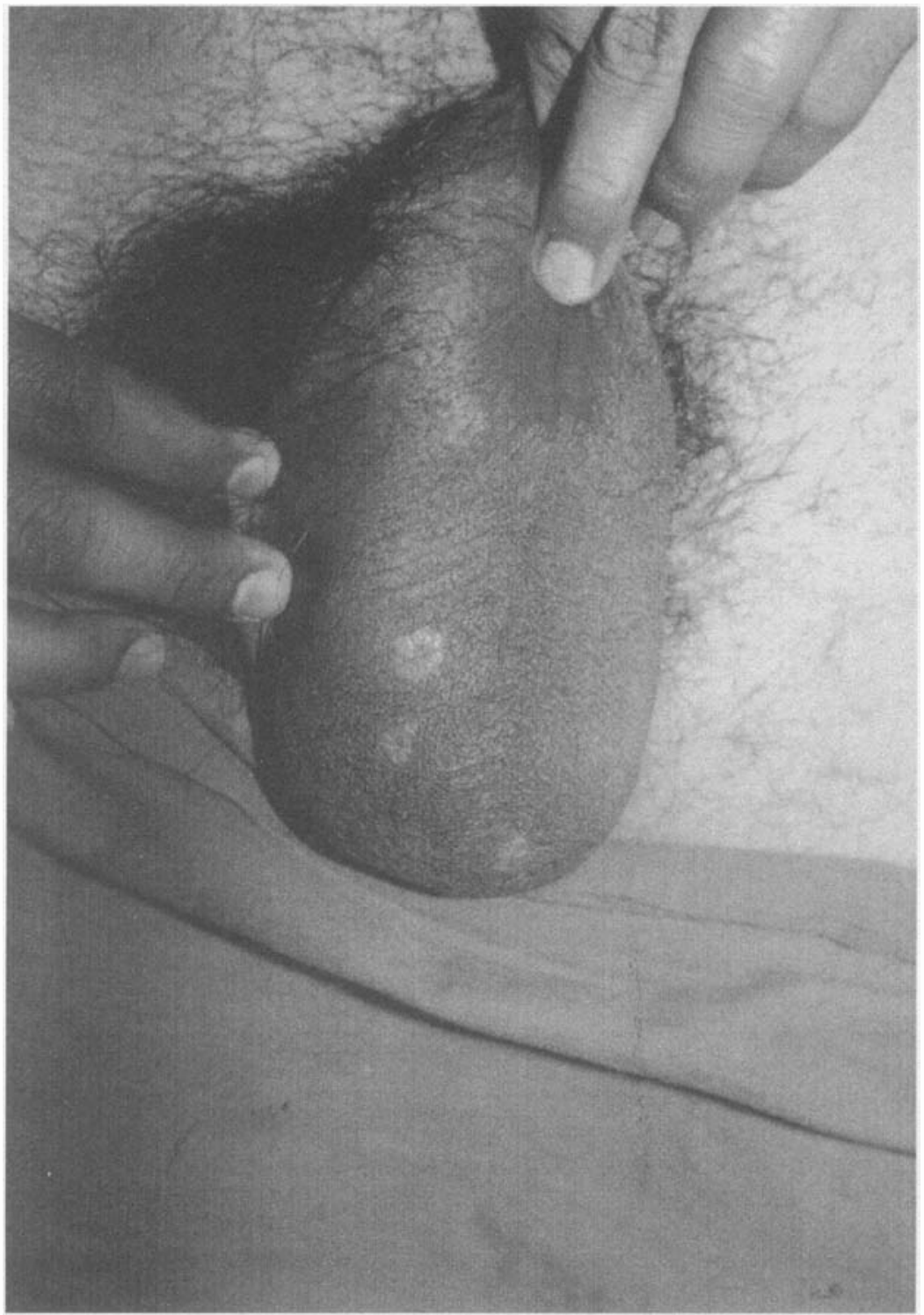

Figure 6. Multiple necrotic ENL lesions on glans penis in LL leprosy.

\section{References}

${ }^{1}$ Fox H, Knott J. Leprous nodules of male genitalia. Int J Lepr, 1932; 2: 445-446.

${ }^{2}$ Indian Association of Leprologists consensus classification. Lepr Ind, 1982; 54: 17.

${ }^{3}$ Kaur S, Kumar B. Study of apparently uninvolved skin in leprosy as regards bacillary population at various sites. Lepr Ind, 1978; 50: 38-44.

4 Arora SK, Mukhija RD, Mohan L et al. A study of cutaneous lesions of leprosy on male genitalia. Ind J Lepr, 1989; 61: 222-224. 
5 Ramu G, Desikan KV. A study of scrotal biopsy in subsided cases of lepromatous leprosy. Lepr Ind, 1979; 51: 341-347.

6 Pandya NJ, Antia NH. The value of scrotal biopsy in leprosy. Lepr Rev, 1974; 45: 145-152.

7 Anish SA. The relationship between surface temperature and dermal invasion in lepromatous leprosy. Int J Lepr, 1971; 39: 848-851.

${ }^{8}$ Kandeel FR, Swerdloff RS. Role of temperature in spermatogenesis and use of heating as a method of contraception. Fertil Steril, 1998; 49: 1-23.

9 Dixit VB, Chaudhary SD, Jain VK et al. Primary involvement of scrotum in tuberculoid leprosy. Ind J Lepr, 1990; 62: $120-122$.

${ }^{10}$ Ramanujam K, Ramu G. Wade's histoid lepromatous leprosy. Report of a clinical study. Lepr Ind, 1969; 4: 293297.

11 Nigam PK, Singh G. Mucosal and genital lesions in histoid leprosy. Int J Dermatol, 1990; 29: 207-208. 